\title{
Spiritual Well-being, Faith, Hope, Anxiety and Loneliness in Oncology Patients: A Descriptive Correlational Study
}

Julia R. Mueller

CedarvilleUniversity, juliamueller@cedarville.edu

Follow this and additional works at: http://digitalcommons.cedarville.edu/nursing theses

Part of the Nursing Commons

\section{Recommended Citation}

Mueller, Julia R., "Spiritual Well-being, Faith, Hope, Anxiety and Loneliness in Oncology Patients: A Descriptive Correlational Study" (2015). Master of Science in Nursing Theses. 15.

http://digitalcommons.cedarville.edu/nursing_theses/15 


\title{
SPIRITUAL WELL-BEING, FAITH, HOPE, ANXIETY AND LONELINESS IN ONCOLOGY PATIENTS: A DESCRIPTIVE CORRELATIONAL STUDY
}

\author{
A thesis submitted in partial fulfillment \\ of the requirements for the degree of \\ Master of Science in Nursing
}

By

JULIA RENAE MUELLER

B.S.N. Cedarville University, 2009

2015

Cedarville University 


\begin{abstract}
Purpose: To test theorized relationships in the newly developed Faith-Hope-Love Model of Spiritual Wellness (FHLMSW). The research questions were: 1) do measures of faith, hope and love correlate with or predict spirituality as defined by FHLMSW in a palliative care population; and 2) do relationships exist between measures of spirituality and physical symptoms and distress among the same palliative care population.
\end{abstract}

Patients and Methods: This was a descriptive correlational study, which included 21 participants with a stage III or IV cancer diagnosis that were receiving palliative care at a community oncology practice, that took place between January 2015 to March 2015. Each participant completed a 46-item survey that measured five concepts: spiritual well-being (SWB), hope, faith, anxiety, and loneliness.

Results: Hope and faith were the best predictors of SWB, accounting for $77.3 \%$ and $81 \%$ of the variance respectively, and showed strong correlations with $\mathrm{SWB}(\mathrm{R}=.882, p=.000$, equal values). Anxiety (fear) negatively correlated with $\mathrm{SWB}(\mathrm{R}=-.523, p=.026)$. The subscales of the loneliness measure negatively correlated with $\operatorname{SWB}(p>.10)$ with the strongest in the Romantic subscale $(\mathrm{R}=.123)$.

Conclusion: This is the first study where spiritual needs were conceptually and operationally defined, measured, and correlated with each other and with a reliable and valid measure of SWB. Relevance to clinical practice: Palliative care patients at the end of life expect nurses to provide spiritual care. Researchers have reported multifaceted benefits associated with support of spiritual needs. If the FHLMSW is found to be valid, this may help nurses provide more effective spiritual care at the end of life.

Keywords: oncology, palliative care, spiritual care, spirituality, spiritual needs, end-of-life 


\section{Dedication and Acknowledgments}

This capstone project is dedicated to my mentor, advisor and friend, Sharon Christman, PhD, $\mathrm{RN}$, who is dedicated to advancing God's Kingdom through nursing and who has facilitated my research with a sharp vision for spiritual care. She taught me research as an undergraduate nursing student and I have had the privilege of learning research from her a second time as a graduate student. Working closely with Sharon over the past year has been one of the most important and formative experiences of my graduate education. She has built into my life for over ten years and words cannot express my gratitude.

The members of my capstone committee, Sharon and Beth Delaney CNS, FNP-BC, ACHPN, model the collaborative effort between researcher and nurse practitioner. They have generously given of their time and expertise to better my work. I thank them for their contribution, advice and clear direction through this process. Beth was at the frontline of patient recruitment and I am thankful for her assiduous efforts. I am grateful to the physicians and medical staff at Dayton Physician Network, who partnered with me and provided the venue for my research.

Many thanks must go also to the Cedarville University Department of Nursing faculty and staff for your feedback after Capstone I and for your continual encouragement. I must acknowledge as well the many friends, colleagues, and librarians who assisted my research efforts over the past year. I am thankful to my parents, brothers and sisters for their love, support and encouragement from the very beginning of my graduate education.

Finally, I am grateful to God for His sustaining grace, and for giving me my dear husband, Trevor, who has been my biggest support. Trevor has kindly listened to hours of spiritual care talk and has consistently encouraged me with a huge smile to work hard unto the Lord. 


\section{TABLE OF CONTENTS}

Page

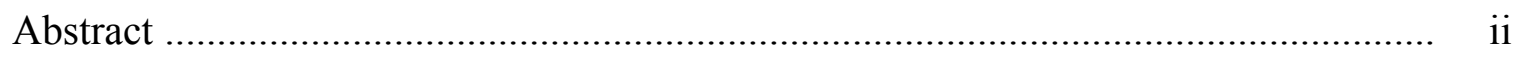

Dedication and Acknowledgements .................................................................

Table of Contents …................................................................................... iv

Chapter

I. Introduction …............................................................................ 1

II. Literature Review: Theoretical Models of SC ...................................... 2

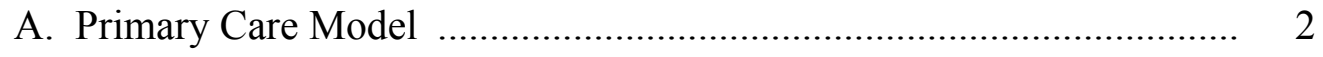

B. Parish Nurse Model ................................................................... 3

C. Careful Model ......................................................................... 3

D. T.R.U.S.T. Model …................................................................. 4

E. Biopsychosocial-Spiritual Model of Care ...................................... 4

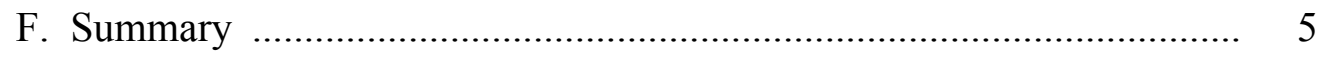

II. Theoretical Model: Faith-Hope-Love Model of Spiritual Wellness ............ 5

A. Relationships Between Spirit and Body ..................................... 7

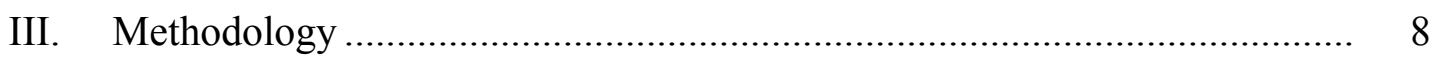

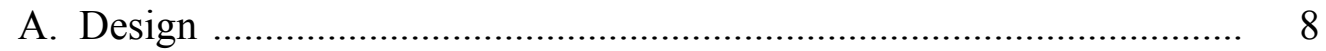

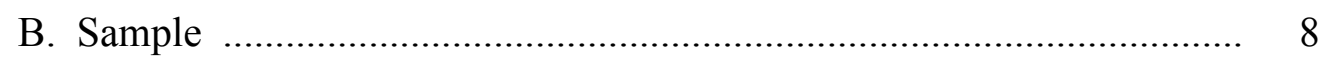

C. Measurement Tools .................................................................... 8

D. Data Collection ....................................................................... 12

E. Statistical Analysis ................................................................. 13

F. Ethical Considerations .......................................................... 14 


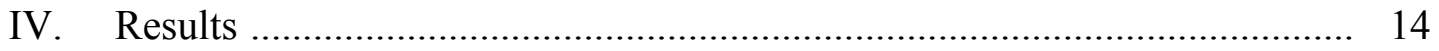

A. Sample Characteristics ………………………………………….... 15

B. Pearson's R Correlations ................................................................ 16

C. Stepwise Linear Regression ………………………....................... 16

D. Physical Symptoms and Distress ……………………..................... 17

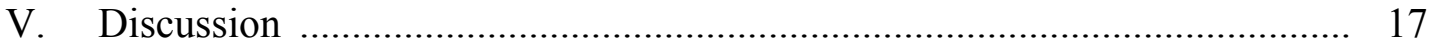

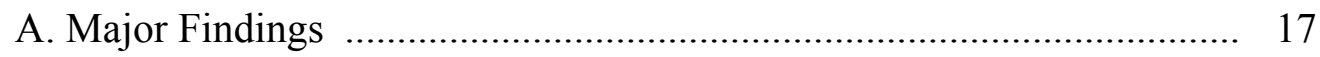

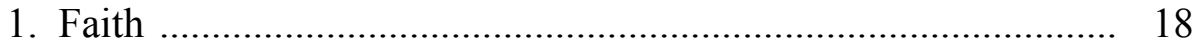

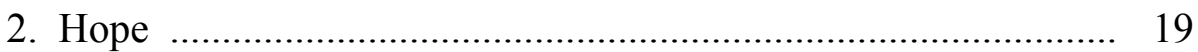

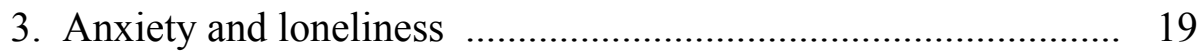

4. Physical symptoms and distress ………………..................... 20

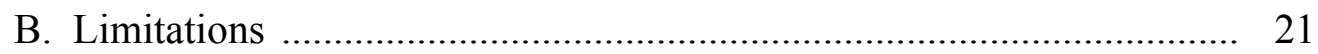

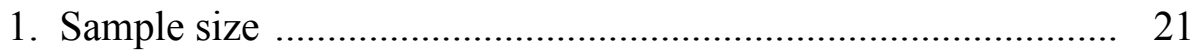

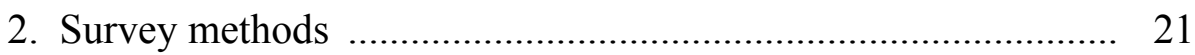

3. Age appropriate questionnaire …………………….............. 22

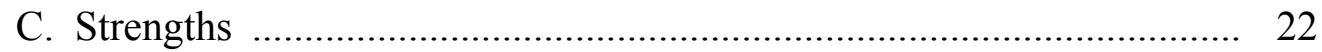

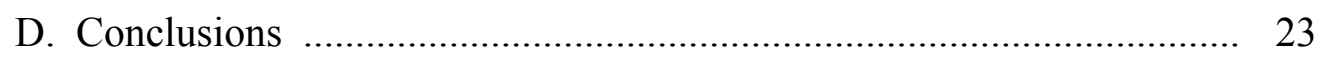

E. Implications for Nursing ………………..................................... 23

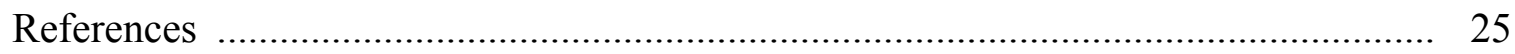


Spiritual Well-being, Faith, Hope, Anxiety and Loneliness in

Oncology Patients: A Descriptive Correlational Study

Palliative care patients at the end of life expect nurses to provide spiritual care (SC;

Balboni et al., 2013). The majority of patients with advanced illness identify SC as important, have spiritual needs and desire nurses to provide SC (Balboni et al., 2013; Pearce, Coan, Herndon, Koenig, \& Abernethy, 2012; Phelps et al., 2012, Hodge \& Horvath, 2011). Major organizations recommend that nurses provide SC and address spiritual needs. The National Consensus Project for Quality Palliative care (2013), a group of US palliative care organizations, developed practice guidelines that recognize spirituality of patients and SC as fundamental aspects of palliative care. The World Health Organization (2014) provides a definition for palliative care that includes assessment and treatment of the spiritual needs of patients. The Joint Commission identifies SC as a priority need for dying patients (Niespodziani \& Hepola, 2011).

Researchers have reported that in outpatient medical settings, support of spiritual needs is associated with greater satisfaction and perceived quality of care, less depression, improved coping, higher quality of life, less aggressive interventions, greater hospice use and decreased medical care costs (Balboni et al., 2011; Vallurupalli et al., 2012; Whitford \& Olver, 2012, Balboni et al., 2010; Astrow, Wexler, Texeira, Kai He, \& Sulmasy, 2007; Balboni et al., 2007; Kristeller, Rhodes, Cripe, \& Sheets, 2005; Brady, Peterman, Fitchett, Mo, \& Cella 1999). In a review published in 2012, Koenig reported the relationships between high religion and spirituality and lower incidence of coronary heart disease, hypertension and cancer mortality. Also in 2012, researchers found that high levels of spiritual well-being (SWB) resulted in lower levels of stress, anxiety and depression (Musarezaie, Esfahani, Ghaleghasemi, Kariamian, \& Ebrahimi). Furthermore, researchers from Duke University reported patients who received less 
SC than desired reported more depressive symptom and less meaning and peace (Pearce et al., 2012).

Patients with incurable cancer have conveyed spiritual concerns as distressing and burdensome, and believe that SC should be addressed as part of cancer care (Winkelman et al., 2011). Even so, many studies reveal that SC is infrequent at the end of life; the majority of patients with advanced illness receive little support for their spiritual needs (Balboni et al., 2013; Phelps et al., 2012; Balboni et al., 2007; Astrow et al., 2007). In 2012, researchers from the Dana-Farber Cancer Institute in Boston, MA found that the majority of patients with advanced cancer (77.9\%) believed SC would have a positive impact on patients; however, only $25 \%$ of patients had previously received SC (Phelps et al., 2012).

\section{Literature Review: Theoretical Models of Spiritual Care}

Most of the published theoretical models of SC have been developed through qualitative methods, literature reviews, historical findings and expert opinion. Some models address patients' perspective regarding spirituality or SC, the nurses' perspective or both. Various worldviews are presented within the models with a broad Christian worldview as the most prevalent.

\section{Primary Care Model}

In 2011, nurses from Colorado developed a conceptual nursing model, reflecting a spiritual-relational view, for the implementation of SC in adult primary healthcare settings (Carron \& Cumbie). The researchers used a descriptive, qualitative design to explore perspectives of spirituality in 14 subjects - older adults, family nurse practitioners, community spiritual leaders/educators, and nuns. These researchers concluded that the nurse practitionerpatient relationship forms the foundation for the exploration of the patient's spirituality. 
Spirituality was conceptually defined and was viewed as a potential resource to help the adult cope with emerging problems (Carron \& Cumbie, 2011). This study was guided by nursing theories, sought to explain the patient-nurse-spirit relationship, and gave ideas for providing SC. However, a definition of the spirit was not provided and spiritual needs were not included in the model. Further, SC interventions were minimally discussed and were based on identification of spiritual support systems used by the patient.

\section{Parish Nurse Model}

Van Dover and Pfeiffer (2007) developed a substantive theory to explain the process Christian parish nurses use to provide SC. Researchers used qualitative methods to interview 10 parish nurses over four years and analyzed over $50 \mathrm{SC}$ encounters with a grounded theory approach. The theory 'Bringing God Near' is a basic social process involving five consecutive phases: trusting God, forming relationships with the patient or family, opening to God, activating or nurturing faith, and recognizing spiritual renewal or growth (van Dover \& Pfeiffer, 2007). This theory is primarily Christian but can be used by any nurse with a faith centered on a personal God who wishes to develop their SC practice (van Dover \& Pfeiffer, 2007). While this model clearly described the steps many Christian parish nurses take to provide SC, there was no definition of spirituality, SWB, or spiritual distress.

\section{Careful Model}

In 2012 a nurse researcher from Ireland described SC from the perspective of the Careful Nursing philosophy and professional practice model (Meehan). Careful Nursing is guided by a Christian worldview, and was supported by several philosophical assumptions. These assumptions defined human being, the existence of an infinite transcendent reality (God), and health. Human was defined as a unitary person, with two distinguishable realities (the psycho- 
spiritual reality of mind and spirit and a bio-physical reality of body), and health was defined as human flourishing (Meehan, 2012). According to the Careful Nursing Philosophy, the foundation of SC involves the implementation of six spirituality-related dimensions and the recognition of intrinsic human dignity (Meehan, 2012). While this model is grounded in philosophy it does not define spirituality, spiritual needs or spiritual distress. Furthermore, a definition of the spirit as a separate entity from the body is not permissible based on the model's presuppositions.

\section{T.R.U.S.T. Model}

A nurse educator and spiritual director developed the T.R.U.S.T. Model for Inclusive Spiritual Care to help health care professionals feel more prepared to address spiritual dimensions of health (Barss, 2012). This model provides an exploratory nonlinear approach to providing SC within five dimensions: traditions, reconciliation, understandings, searching and teachers (Barss, 2012). Each dimension is associated with initial assessment questions consisting of closed questions followed by open questions. Spiritual assessment identifies spiritual needs and is intimately intertwined with SC. Patients self-define "the spiritual" or relevant spiritual needs (Barss, 2012, p. 29). This model focuses on both nurse and patient and defines inclusive SC, trust and healing (similar to SWB). However, the spirit, spirituality, and spiritual distress are not discussed.

\section{Biopsychosocial-Spiritual Model}

In 2002, a physician and Franciscan philosopher proposed The Biopsychosocial-Spiritual Model of Care, which was grounded in the anthropological philosophy that conceptualizes humanity as beings in relationship (Sulmasy). According to this model, every person has a spiritual history and when illness strikes, the totality of the person is affected including the 
interrelated biological, psychological, social and spiritual aspects (Sulmasy, 2002). Sulmasy addressed the concepts of spiritual needs and SWB and questioned whether these concepts could be measured. Thus, he proposed several measurement tools that he suggests might be acceptable.

\section{Summary}

There are several published theoretical models of SC that can help nurses better understand the human spirit, spirituality, SWB, spiritual distress, and spiritual needs. However, there is no one theoretical model of SC that conceptualizes all of these concepts, nor do any of these models theorize the types of relationships between these concepts. As a result, Christman and Mueller (2015) developed the Faith-Hope-Love Model of Spiritual Wellness (FHLMSW) to address the limitations found in the other models of SC.

\section{Theoretical Model: The Faith-Hope-Love Model of Spiritual Wellness}

The Faith-Hope-Love Model of

Spiritual Wellness (FHLMSW) (Figure 1),

developed from a Christian worldview, defines key spiritual relationships that will be tested in this study (Christman and Mueller, 2015). The FHLMSW proposed that all human persons are dualistic in nature, which means they have a non-

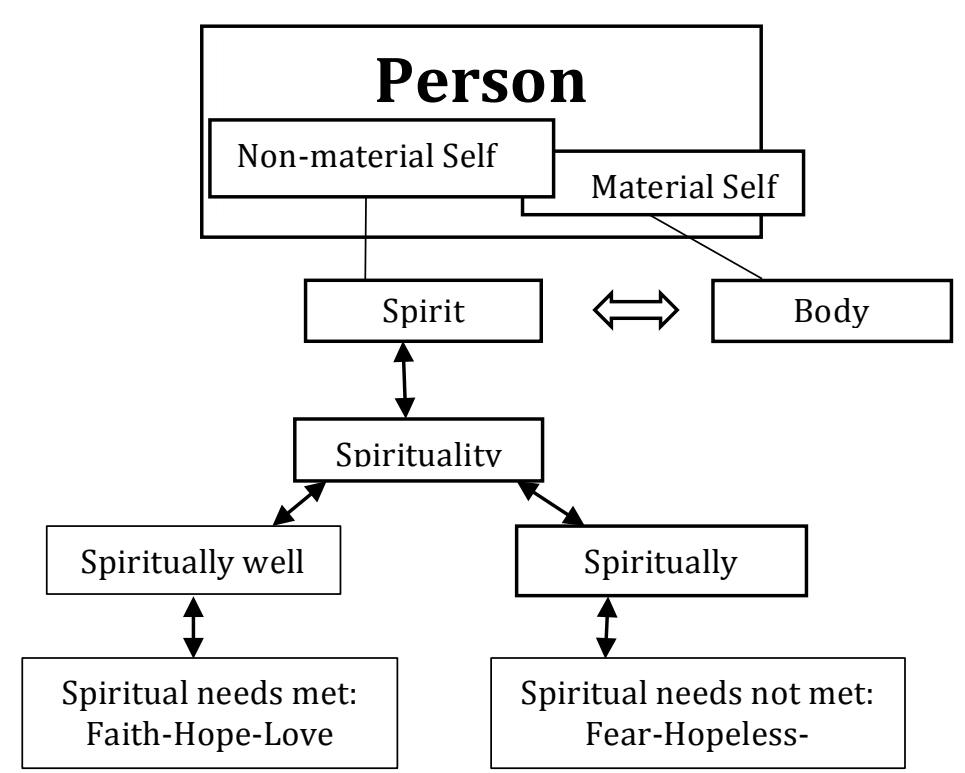
material self (spirit) and a material self (body). This relationship is causal and dependent. In other

Figure 1. The Faith-Hope-Love Model of Spiritual Wellness (Christman \& Mueller, 2015) 
words a physical injury is likely to cause spiritual pain; or a weakened spirit may result in physical fatigue.

The spirit is the immortal seat of emotions, is able to interact with other spirits, both divine and human, and able to develop relationships with other spirits. The overall health of the human spirit is dependent on the types of relationships that it develops, and whether these relationships meet the spirit's needs for faith, hope and love. When a person's spiritual needs are met, they can be described as spiritually well and therefore they have meaning and purpose in their life.

This model identifies three spiritual needs as essential to every human spirit: faith, hope, and love. Faith is conceptually defined as:

A belief or trust in someone or something. For the Christian this need is primarily met through faith in Jesus Christ, however, all people need to have faith in something whether temporal or eternal. When this need is not met, fear is the result (Christman \& Mueller, 2015, p. 10).

Hope is conceptually defined as:

A person's confidence that their faith has not been misplaced. For the Christian, this need is met by their hope that Jesus is powerful enough to keep His promise of life with Him in heaven; however, all people have a need to be confident that what they believe will come to pass. When this need is not met, hopelessness is the result (Christman \& Mueller, 2015, p. 10).

Love is conceptually defined as:

Every person's greatest spiritual need and for the Christian, this need is met by a love relationship with Jesus Christ. However, all people have the need to receive love from 
others through expressions of patience, kindness, forgiveness, humbleness, protection from harm, truthfulness, endurance, and selflessness. When the need for love is not met, loneliness is the result (Christman \& Mueller, 2015, p. 11).

Relationships hypothesized in this theoretical model have never been tested, and yet the authors of the model suggest that they should be tested before the model is used to develop SC interventions. Therefore, the primary purpose of this study was to validate the model and determine whether measures of faith, hope and love could predict spirituality as defined by FHLMSW. The research question was: do measures of faith, hope and love correlate with or predict spirituality as defined by FHLMSW in a palliative care population?

\section{Relationships Between Spirit and Body}

In palliative care populations, distress and symptom management are the intended outcome as opposed to cure (Hoffman, Zevon, D'arrigo, \& Cecchini, 2004; Philip, Smith, Craft, \& Lickiss, 1998). The National Comprehensive Cancer Network (NCCN; 2013) conceptually defines distress as a "multifactorial unpleasant emotional experience of a psychological social, and/or spiritual nature that may interfere with the ability to cope effectively with cancer, its physical symptoms and its treatment" (p. DIS-2). Furthermore, the most common physical symptoms reported in the palliative care population include: pain, tiredness, drowsiness, nausea, anorexia, shortness of breath, depression, anxiety and constipation. Researchers have reported a relationship between spiritual and physical health, and the FHLMSW hypothesizes a causal and dependent relationship between the spirit and the body (Christman and Mueller, 2015; Whitford \& Olver, 2012; Brady et al., 1999). In order to test the relationship between the spirit and the body, the secondary purpose of this study was to describe the relationship between measures of spirituality and reports of physical symptoms and distress within a palliative care population. 
The second research question was: do relationships exist between measures of spirituality and physical symptoms and distress among the same population?

\section{Methodology}

\section{Design}

A descriptive correlational design was used to examine the spiritual health of oncology patients who had been identified with stage III-IV cancer and referred to the palliative care APRN at a private community oncology office in the Midwest. Determined by the FHLMSW, the variables measured in this study were SWB, faith, hope, anxiety, loneliness, physical symptoms and distress.

\section{Sample}

Our population of interest included adult advanced cancer patients (stage IV) receiving outpatient palliative care but not hospice care. This was a convenience sample drawn from the population and inclusion criteria were: an active cancer diagnosis, receiving some type of cancer treatment (whether curative or palliative); cancer treatment was defined as pharmacological, nonpharmacological, end-of-life care or any type of palliative care. Exclusion criteria included age less than 18 years, unable to read or write English, and/or a latent cancer diagnosis (defined as cancer that was successfully treated or in remission). Recruitment took place between January 2015 and March 2015.

\section{Measurement Tools}

Spiritual well-being was measured using the Meaning subscale of the Functional Assessment of Chronic Illness Therapy - Spiritual Well-Being Scale (FACIT-Sp), a multidimensional measure of SWB that is widely used in cancer research (Canada et al., 2013; Peterman, Fitchett, Brady, Hernandez, \& Cella, 2002). This 12-item questionnaire was 
originally developed in 1998 by a professor and doctor of psychiatry and psychology and uses a five-point Likert scale to evaluate three factors: meaning, peace and faith (Bredle, Salsman, Debb, Arnold, \& Cella, 2011; Murphy et al., 2010). Peterman et al. (2002) originally validated the FACIT-Sp with a large diverse sample size and found two subscales: an 8-item Meaning/Peace subscale and a 4-item Faith subscale. More recent factor analyses have revealed that the Meaning/Peace subscale is more informative when treated as two separate factors, both measuring different aspects of religion/spirituality; meaning assesses a cognitive dimension, whereas peace measures an affective dimension (Murphy et al., 2010; Canada, Murphy, Fitchett, Peterman, \& Schover, 2008). Cronbach's alpha was reported as 0.88 for the total FACIT-Sp and 0.78, 0.83, 0.87 for the Meaning, Peace and Faith subscales respectively (Murphy et al., 2010). However, we felt that for this small pilot study, the subscales of Meaning and Peace (combined) better reflected our definition of spirituality, and therefore, we chose to use a 2-factor FACIT-Sp for analysis.

Faith was measured with the Faith subscale of the FACIT-Sp, as described earlier, and assesses the role of faith in illness (Peterman et al., 2002). This 4-item subscale measures entries such as "I find comfort in my faith" and "My illness has strengthened my faith or spiritual beliefs." Cronbach's alpha is 0.87 and using partial correlations, faith was negatively associated with mental health (Murphy et al., 2010).

The concept of hope was operationalized as a score on the Herth Hope Index (HHI), which is a 12 -item questionnaire using a Likert-format with three subscales: 1) temporality and future, 2) positive readiness and expectancy and 3) interconnectedness (Herth, 1992). The HHI was developed in 1992 by a nurse researcher and is one of the most widely used measures to assess hope (Phillips-Salimi, Haase, Kintner, Monahan, \& Azzouz, 2007). Cronbach's alpha was 
reported as 0.97 with a two-week test-retest reliability of 0.91 (Herth, 1992). Criterion related validity was established through moderate to high correlations between the HHI and the original HHS $(r=.92)$, the Existential Well-Being Scale $(r=.84)$, and the Nowotny Hope Scale $(r=.81$; Herth, 1992). Divergent validity was confirmed by a correlation between the HHI and the Hopelessness Scale $(r=-0.73$; Herth, 1992). Construct validity was supported by a factorial analysis of the three subscales (Herth, 1992).

Fear was operationalized as anxiety and was measured using the Generalized Anxiety Disorder (GAD)-7 scale, a 7-item measure for evaluating the presence and severity of GAD using a four-point Likert-scale (Spitzer, Kroenke, Williams, \& Lowe, 2006). Developed by one of the most influential psychiatrists of the twentieth century and colleagues, this instrument is one of the few GAD measures specifically linked to the DSM-IV criteria (Spitzer et al., 2006; Spiegel, 2005). Cronbach's alpha was reported as 0.92 and test-retest reliability was 0.83 (Spitzer et al., 2006). There was a strong association between increasing GAD-7 severity scores and worsening function on all six Medical Outcomes Study Short-Form General Health Survey, which confirmed construct validity (Spitzer et al., 2006). Also, convergent validity was good, as demonstrated by correlations between the GAD-7 and two anxiety scales: the Beck Anxiety Inventory $(\mathrm{r}=0.72)$ and the anxiety subscale of the Symptom Checklist-90 $(\mathrm{r}=0.74$; Spitzer et al., 2006).

Loneliness was operationalized as the score on the 15-item Social and Emotional Loneliness Scale for Adults (SELSA-S); a seven-point Likert scale that measures social and emotional loneliness and includes three subscales (Romantic, Family and Social) (DiTommaso, Brannen, \& Best, 2004). Cronbach's alpha was reported as 0.87 (Romantic), 0.89 (Family) and 0.90 (Social; DiTommaso et al., 2004). Concurrent and discriminate validity was confirmed 
with significant correlations between each subscale on the SELSA-S and the SELSA long version subscales $(r=0.18-0.85)$ and the University of California, Los Angeles, Loneliness Scale -Version 3 (UCLA-3; $r=0.34$ - 0.73; DiTommaso et al., 2004). Additionally, strong associations between the SELSA-S and eight different personality and adjustment measures (self-esteem, social skills, coping style, liking for people, interpersonal trust, social intimacy, mental symptomatology and satisfaction with life) support concurrent and convergent validity (DiTommaso et al., 2004).

Physical symptoms were operationalized as the score on the revised version of the Edmonton Symptom Assessment System (ESAS-r). The ESAS-r was developed from the ESAS, an instrument first introduced in 1991 by Bruera, a palliative care and hospice physician, and colleagues from Alberta, Canada (Bruera, Kuehn, Miller, Selmser, \& MacMillan, 1991). The ESAS-r is a widely used self-report symptom intensity tool for assessing nine common symptoms of advanced cancer (pain, tiredness, nausea, depression, anxiety, drowsiness, appetite, well-being, shortness of breath [SOB]), with an optional tenth patient-specific symptom all measured on an 11-point numerical rating scale (Watanabe et al., 2011). Based on a systematic review on the reliability and validity of the ESAS, Cronbach's alpha ranged from 0.79-0.93 under the assumption that the ESAS has no factors and represents a latent construct (Richardson \& Jones, 2009). Further, Wantabe (2011) found that the ESAS-r could reliably replace the ESAS. Reliability was confirmed with positive correlations $(0.45-0.85)$ between individual ESAS items and scores elicited from alternative tools such as Memorial symptoms assessment scale (SOB, appetite, nausea, nervous, depression); the Symptom Distress Scale (nausea, SOB, pain, appetite, depression); and the Brief Pain Inventory (pain; Richardson \& Jones, 2009). Concurrent reliability was shown with kappa values of 0.46 to 0.61 for agreement with the 
Rotterdam Symptom Checklist (SOB, anxiety, appetite, nausea and depression) and the Brief Pain Inventory (current pain, pain relief; Philip et al., 1998).

Distress was operationalized as results on The Distress Thermometer (DT) and The Problem List (PL), two self-report measures developed by the NCCN Distress Management panel in 1999 with updated distress management guidelines published in 2013 (NCCN, 2013; Holland, 1999). The DT, a global distress measure is a visual analog scale in the form of a thermometer from zero (no distress) to ten (extreme distress). The PL, on the same page as the DT, asks the patient to identify sources of distress from 39 items in five categories (practical, family, emotional, spiritual/religious and physical). Cronbach's alpha for the combined scales termed the NCCN Distress Management Screening Measure (DMSM) - was reported as 0.81 overall and for the subscales Cronbach's alphas were the following: physical (0.92), emotional (0.88), family (0.59), practical (0.42, increased to 0.61 with removal of one item "work/school") and philosophical ( 0.31 , increased to 0.44 with removal of one item "loss of faith;" Hoffman et al., 2004). Convergent validity was established by correlations between the DMSM and the Brief Symptom Inventory (BSI) Global Severity Index and BSI subscales Depression $(r=0.54)$, Anxiety $(r=0.68)$ and Hostility $(r=0.50)$, all with significance of $\mathrm{p}<0.001$ (Hoffman et al., 2004). Divergent validity was demonstrated by a correlation of $\mathrm{R} \leq 0.43$ with the BSI scales that suggested psychopathology not characterized by general distress (Hoffman et al., 2004).

\section{Data Collection}

Subjects were recruited by a palliative care APRN who identified a patient as eligible to participate in the study. The APRN gave each eligible patient a brochure with information about the study and told the patient they could complete the survey in the office or at home. Options for in office completion included online (via iPad) or on paper and option for at home 
completion included online (via email hyperlink), on paper (via mail with stamped return envelope), or by phone. After the APRN informed the patient about the study, the medical assistant (MA) or secretary asked the patient prior to check out if they desired to participate. Once the patient agreed to participate the office staff preceded to ask which survey format they preferred. If the patient chose to complete the survey in office the MA administered the survey. If the patient chose to complete the survey at home, the MA obtained the patient's email address, address or phone number so that the primary investigator could appropriately administer the survey. Qualtrics online computer software was used to administer the online questionnaire and collect data. Additional data was collected after the survey was completed using a chart review method, and included gender, age, diagnosis, treatment and ESAS and distress data.

\section{Statistical Analysis}

Descriptive statistics were used to analyze demographic data, clinical characteristics and survey scores including mean, median, mode, frequencies and standard deviation. To address hypothesized relationships of the FHLMSW, Pearson's correlations examined relationships between SWB (FACIT-Sp Meaning/Peace [M/P] subscale) and the following variables: faith (FACIT-Sp Faith subscale), hope (HHI), loneliness (SELSA-S Romantic, Family and Social subscales), anxiety (GAD-7) and distress (NCCN DT). To address predictive value of the hypothesized relationships, a stepwise linear regression, using forward selection with adjusted $\mathrm{R}$ square, was used to assess the following variables as a group best associated with SWB: hope, loneliness (SELSA-s Romantic subscale) anxiety and faith. The secondary purpose was explored with a linear regression to evaluate relationships between SWB and physical symptoms (ESAS) and distress. A two-sided $p<.05$ was considered significant. Analyses were performed with SPSS statistical software version 22 . 


\section{Ethical Considerations}

Ethical approval was received from Cedarville University’s Institutional Review Board.

A thorough explanation about the purpose and benefits of this study was given to each subject prior to distributing the questionnaire. All subjects were informed that participation was voluntary and palliative care offered by the APRN was not dependent on participation.

Data collection was not anonymous, but all data was reported in aggregate, and patient confidentiality was maintained in accordance with HIPAA and IRB. In an effort to reduce subject fatigue, they were told they could have a family member or close friend fill out the questionnaire on their behalf if physical symptoms were overwhelming. Furthermore, the survey was kept as short as possible to minimize subject fatigue. A pilot study, specifically addressing subject fatigue, revealed that while completion of the survey took each subject an average of eight minutes and 30 seconds, they reported that it only felt like three to five minutes.

Table 1. Characteristics of Sample Patients $(\mathrm{N}=19)$

\begin{tabular}{|c|c|c|}
\hline Characteristic & $\begin{array}{c}\text { No. of } \\
\text { Patients }\end{array}$ & $\%$ \\
\hline \multicolumn{3}{|l|}{ Sex } \\
\hline Male & 10 & 52.6 \\
\hline Female & 9 & 47.4 \\
\hline \multicolumn{3}{|l|}{ Age, years } \\
\hline Mean & \multicolumn{2}{|c|}{73.5} \\
\hline SD & \multicolumn{2}{|c|}{11.2} \\
\hline \multicolumn{3}{|l|}{ Marital Status* } \\
\hline Married & 11 & 52.4 \\
\hline Single/never married & 5 & 23.8 \\
\hline Divorced & 3 & 14.3 \\
\hline Other & 2 & 9.6 \\
\hline \multicolumn{3}{|l|}{ Cancer Diagnosis } \\
\hline Lung cancer & 11 & 57.9 \\
\hline Prostate cancer & 2 & 10.5 \\
\hline Other** & 6 & 31.8 \\
\hline \multicolumn{3}{|l|}{ Current Cancer Treatment } \\
\hline Chemotherapy & 8 & 42.1 \\
\hline Palliative (only) & 4 & 21.1 \\
\hline Chemo + radiation & 3 & 15.8 \\
\hline Radiation & 2 & 10.5 \\
\hline None & 2 & 10.5 \\
\hline \multicolumn{3}{|l|}{ Religion* } \\
\hline Christian & 10 & 47.6 \\
\hline Protestant & 6 & 28.6 \\
\hline Catholic & 3 & 14.3 \\
\hline Other & 2 & 9.5 \\
\hline \multicolumn{3}{|l|}{ Attendance Religious } \\
\hline Gatherings** & 10 & 47.6 \\
\hline Weekly & 4 & 19.0 \\
\hline Never & 3 & 14.3 \\
\hline $2-3 x$ per mo & 2 & 9.5 \\
\hline $1-5 x$ per $y r$ & 1 & 4.8 \\
\hline $6-12 x$ per yr & 1 & 4.8 \\
\hline \multicolumn{3}{|c|}{ Weekly (limited by illness) } \\
\hline
\end{tabular}

\section{Results}




\section{Sample Characteristics}

Of 22 patients that agreed to participate in the study, one was excluded related to poor survey completion for a survey total of $\mathrm{N}=21$. Nonparticipants and refusal rates were not recorded, but according to the medical assistant who distributed the surveys, the most common reasons for refusal were feeling too sick, feeling overwhelmed with new information discussed during the palliative care visit or not having enough time. The most common survey method chosen was paper-pencil $(52 \%, \mathrm{~N}=11)$, followed by phone $(24 \%, \mathrm{~N}=5)$, mail $(14 \%, \mathrm{~N}=3)$ and online $(10 \%, \mathrm{~N}=2)$. The rate of completion and return of mailed surveys was $100 \%$, while email responses were $0 \%$. The two online surveys were anonymous, so we were unable to collect demographic data and ESAS and distress data. However, the online survey included marital status, religious affiliation and attendance to religious gatherings, which were considered in demographic analysis.

Characteristics of sample patients $(\mathrm{N}=19)$ and anonymous patients are reflected in Table 1. Mean age for the sample was 73.5 years, $52.6 \%$ were male and $90 \%$ claimed a JudeoChristian religion. The majority of diagnoses were lung cancer because the palliative care APRN was in process of expanding her population from only lung cancer referrals to any type of end-stage cancer referrals.

Nearly $60 \%$ of the population was receiving chemo, radiation of both. Nearly one third $(28.6 \%)$ of the patients $(\mathrm{N}=6)$ had missing data on

\begin{tabular}{|c|c|c|c|c|}
\hline \multicolumn{5}{|c|}{ Table 2. Survey Frequencies } \\
\hline Survey & Mean & SD & Max Score & Interpretation \\
\hline HHI & 40.1 & 6.55 & 48 & Higher score $=$ high hope \\
\hline SELSA-S (Romantic) & 3.12 & 1.66 & 7 & Higher score $=$ high loneliness \\
\hline SELSA-S (Family) & 2.19 & 1.37 & 7 & Higher score $=$ high loneliness \\
\hline SELSA-S (Social) & 2.36 & 1.19 & 7 & Higher score $=$ high loneliness \\
\hline GAD-7 & 11.75 & 6.21 & 21 & Higher score $=$ high anxiety \\
\hline FACIT-Sp (M/P) & 26.30 & 6.14 & 32 & Higher score $=$ high $\mathrm{M} / \mathrm{P}$ \\
\hline FACIT-Sp (Faith) & 13.37 & 3.55 & 16 & Higher score $=$ high faith \\
\hline
\end{tabular}
one or more of the sub- 
surveys (HHI, SELSA-S, FACIT-Sp, and GAD-7) with the most common being the Social subscale of the SELSA-S. There were no statistical ( $\mathrm{t}$-test) differences between gender and levels of SWB (M/P subscale), faith, hope and loneliness (Social, Family and Romantic subscales). Survey frequencies are described in Table 2.

\section{Pearson's R Correlations}

Pearson's R calculations evaluating relationships between SWB (FACIT-Sp M/P subscale) and multiple variables are presented in Table 2. The following question was answered: did hope, loneliness, anxiety (fear) and faith correlate with SWB? Hope and faith strongly correlated with $\mathrm{SWB}(\mathrm{M} / \mathrm{P})$ with equal $\mathrm{R}$ values of .882 and significance of $p=.000$. Anxiety (fear) negatively correlated $(\mathrm{R}=-.523)$

with SWB showing significance $(p=.026)$.

Each subscale of the SELSA-S, representing loneliness, negatively correlated with spirituality, but did not reveal significant relationships. The strongest relationship was found in the Romantic subscale.
Table 2. Pearson's Correlation Spiritual well-being (meaning and peace)

\begin{tabular}{|c|c|c|c|}
\hline \multicolumn{4}{|c|}{$\begin{array}{l}\text { Table 2. Pearson's Correlation } \\
\text { Spiritual well-being (meaning and peace) }\end{array}$} \\
\hline Variable & $\begin{array}{c}\text { Correlation } \\
(\mathrm{R})\end{array}$ & $\begin{array}{c}\text { Significance } \\
\text { (2-tailed } p \text {-value) }\end{array}$ & $\mathrm{N}$ \\
\hline Hope & $.882 * *$ & .000 & 19 \\
\hline Loneliness (Romantic) & -.383 & .095 & 20 \\
\hline Loneliness (Family) & -.262 & .278 & 19 \\
\hline Loneliness (Social) & -.263 & .292 & 18 \\
\hline Anxiety (Fear) & $-.523 *$ & .026 & 18 \\
\hline Faith & $.882 * *$ & .000 & 20 \\
\hline Distress & $.775^{*}$ & .024 & 8 \\
\hline
\end{tabular}

\section{Stepwise Linear Regression}

The results of hierarchical regression analysis with models for hope (HHI) and faith (FACIT-Sp Faith subscale) are presented in table 3. The research question was: could faith, hope and love (loneliness) predict SWB? A stepwise linear regression was conducted to evaluate whether hope, loneliness (SELSA-s Romantic subscale) anxiety (fear) and faith (FACIT-Sp Faith subscale) could predict SWB (FACIT-Sp M/P subscale). At step 1 of the analysis hope entered into the regression equation and was significantly related to $\mathrm{SWB}, \mathrm{F}=55.33, p=.000$. 
The multiple correlation coefficient was $.887(\mathrm{R})$, and $\mathrm{R}^{2}$ was .787 indicating approximately $77.3 \%$ of the variance of the SWB could be accounted for by levels of hope. Faith entered into the equation at step 2 of the analysis and was significantly related to $\mathrm{SWB}, \mathrm{F}=36.70, p=.000$. The R square increased to .840 explaining a significant proportion $(81 \%)$ of the total variance in SWB. Loneliness and anxiety did not enter the equation at step three $(\mathrm{t}=-.652, p>.05$ and $\mathrm{t}=$ $.417, p>.05$ respectively).

Hope and faith were the best predictors of SWB $(\mathrm{M} / \mathrm{P})$. Of the three

\begin{tabular}{|c|c|c|c|c|c|c|}
\hline \multicolumn{7}{|c|}{ Table 3. Stepwise Regression Meaning and Purpose } \\
\hline Model & Variable & $\mathrm{R}$ & $\mathrm{R}$ Square & $\begin{array}{c}\text { Adjusted R } \\
\text { Square }\end{array}$ & $\mathrm{F}$ & $\begin{array}{c}\text { Significance } \\
(p \text {-value })\end{array}$ \\
\hline 1 & Hope & .887 & .787 & .773 & 55.332 & .000 \\
2 & Faith & .916 & .840 & .817 & 36.704 & .000 \\
\hline
\end{tabular}

SELSA-S subscales, the romantic subscale was used in the stepwise regression to represent loneliness because it revealed the strongest negative correlation with spirituality and had the highest number of subjects included $(\mathrm{N}=20)$.

\section{Physical Symptoms and Distress}

Pearson's R correlation and linear regression were used to answer the question; did relationships exist between measures of spirituality and physical symptoms and distress? Pearson's R correlation calculated a strong correlation (.775) between distress and spirituality that was statistically significance $(p=.024)$, however, data was limited with $\mathrm{N}=8$. A linear regression established that the nine physical symptoms on the ESAS could not statistically significantly predict SWB (FACIT-Sp M/P subscale). Data was limited by N=11. Also, distress could not be added to the aforementioned stepwise regression because of limited number $(\mathrm{N}=8)$.

\section{Discussion}

\section{Major Findings}


The results of our study provide preliminary evidence that supports the FHLMSW. We hypothesized that there would be predictive relationships between SWB and faith (fear [anxiety]), hope (hopelessness), and love (loneliness). In this study relationships were found with the strongest predictive relationships between SWB (M/P) and faith and hope. Although not predictive, a significant negative correlation was found between SWB and anxiety (fear). While not statistically significant, loneliness negatively correlated with SWB (M/P). These negative correlations were expected based on the FHLMSW. No relationships were found between physical symptoms and SWB, but results were limited by insufficient data. Preliminary data suggests a high significant correlation between distress and SWB (M/P), but, again, these results are inconclusive based on limited data.

\section{Faith.}

The relationship of faith and its predictive nature on spirituality, specifically with oncology patients, has not been widely studied in literature. The majority of oncology researchers examine faith in relation to quality of life (QOL), coping during illness or adjustment to cancer (Whitford \& Olver, 2012; Yanez et al. 2009). Yanez et al. (2009) found that faith was uniquely related to perceived positive life changes following a cancer diagnosis and that patients with high levels of faith were able to find comfort and strength in their set of beliefs.

Researchers from Evanston, IL found that faith has evidenced a smaller, but significant relationship with QOL when compared to the stronger relationship of meaning and purpose with QOL in oncology patients (Brady et al. 1999). Whitford \& Olver (2012) found conflicting evidence, in a study of patients newly diagnosed with cancer, which revealed that faith, a dimension of spirituality, did not significantly contribute to QOL, however, results were in the right direction to support some contribution to QOL. Further, faith is presumed to act as a 
"nurturer and channel of expression" of meaning and purpose, a potent factor in spirituality, as it relates to QOL (Elkins et al., 1988, p. 6 as quoted by Brady et al., 1999). Peterman et al. (2002) found that the Faith subscale of the FACIT-Sp correlated with measures of religion and spirituality (i.e. organizational and non-organizational religious activity, spiritual beliefs and personal religiousness). In our study, $82 \%$ of the variance in SWB (M/P) was accounted for in faith. While our purpose was not consistent with the above literature, our results supplement the exploration of faith as measured using the FACIT-SP in oncology patients.

\section{Hope.}

Contrasting faith, hope has been widely studied in oncology nursing literature. Our findings that hope accounts for $77 \%$ of the variability in SWB (M/P) are consistent with prior studies that reveal positive correlations with hope and SWB (Butt, 2011). The Existential WellBeing subscale of an instrument similar to the FACIT-Sp has been shown to correlate with hope, which provides further evidence that hope relates to spirituality (Brady et al., 1999; Mickley, Soeken \& Belcher, 1992). Based on a literature review of hope in adults with cancer, the FHLMSW addresses gaps in the literature, by addressing the dynamic nature of hope versus hopelessness and by providing a framework to assist nurses in viewing hope from the patient's perspective (Butt, 2011). Further, hope and its opposite, hopelessness, have frequently demonstrated a significant impact on physical and emotional well-being and have been reported to interact with all dimensions of life (Butt, 2011; Rosenfeld et al., 2011). Our findings support that hope indeed has an impact on spirituality, an integral part of every person.

\section{Anxiety and loneliness.}

Current oncology research indicates the prevalence of anxiety and loneliness in patients with cancer; however, none of these studies relate these variables to spirituality or SWB (Chien, 
Liu, Chien, \& Liu, 2014; Watts et al., 2014; Yang et al., 2013). Anxiety is most often studied alongside depression, whereas loneliness is consistently compared to social support and, less frequently, depression and hopelessness (Watts et al., 2014; Pehlivan, Ovayolu, Ovayolu, Sevinc, \& Camci, 2012; Sahin \& Tan, 2012). Our results revealed a moderately strong negative correlation between anxiety (fear) and SWB and a negative correlation between loneliness and spirituality. While the latter correlation was not significant, our results were in the right direction to support the hypothesis of an inverse relationship between loneliness and spiritual wellness. These findings represent new relationships in oncology literature but require additional research with a larger sample size to draw any such conclusions.

\section{Physical symptoms and distress.}

Results exploring the relationship between physical symptoms and distress were severely limited based on available data, $\mathrm{N}=10(\mathrm{~N}=9$ for ESAS well-being variable $)$ and $\mathrm{N}=8$ respectively. No relationships were found between physical symptoms outlined by the ESAS and SWB (M/P). In contrast, Brady et al. (1999) emphasized physical symptoms and SWB as a clinical target, in that the ability to enjoy life even in the midst of physical symptoms was related to SWB. In other words, higher SWB operates in a way that helps "people continue to value themselves and their lives, despite the symptom, as well as to maintain the strength to endure the symptom" (Brady et al., 1999, p. 419). Whitford and Olver (2012) also reported that a strong sense of meaning and peace during times of illness might impact the experience of chronic symptoms.

Preliminary data suggests a high significant correlation between distress and SWB (M/P), which is consistent with current literature. Distress has been widely studied in oncology patients, although, few studies explore the relationship between distress and SWB (NCCN, 2013). One 
study found that SWB is closely related to the physical and psychological symptoms of distress in advanced cancer patients (Kandasamy, Chaturvedi \& Desai, 2011). The NCCN (2013) identifies SC as an important consideration when managing cancer related distress and included "spiritual concerns" on the PL.

\section{Limitations}

\section{Sample size.}

Limitations of the study include small sample size, one location, surveying methods and age appropriate questionnaires. Nearly one-third $(\mathrm{N}=6)$ of the patients had missing data on one or more of the sub-surveys (HHI, SELSA-S, FACIT-Sp and GAD-7). Table 2 details the number of sub-surveys that we were able to correlate with the M/P subscale of the FACIT-Sp with N ranging from 18 to 20 . The small sample size limits generalizability of the findings and increases the risk of type II error. A convenience sample was drawn from one location resulting in a sample with primarily Judeo-Christian religious affiliation.

\section{Survey methods.}

Surveying methods resulted in a lack of environmental control. The researchers intended for most patients to take the survey online, however, most preferred paper/pencil questionnaires. Those who did not have time to complete the survey in the office desired to take the survey at by phone or mail rather than email. One patient said that they were receiving many emails from healthcare providers and that, most likely, the emailed survey would be missed. Primary complaints about the iPad were that the font was too small or that they did not know how to use the iPad. We corrected the font size by changing the Internet browser to one that enabled a zoom function. The MA helped some patients use the iPad when she was available; even still, one patient lost all their data when trying to submit the survey. Five patients completed the survey 
over the phone, which may have influenced the nature of the answers. For example, a patient may be more likely to give positive answers (i.e. I have high levels of meaning and purpose), rather than negative answers because they are speaking to a person as opposed to answering in the privacy of their own thoughts.

\section{Age appropriate questionnaires.}

The primary researcher noticed that some patients had difficulty understanding the survey questions and/or the scaling methods, both over the phone and in the office. The survey required a higher degree of cognitive reasoning and reading comprehension, which may have been more difficult for our patient population with a mean age of 73.5 years. Various questions contradicted each other and were repetitive, which may account for missing data; some questions had "N/A" written by them, others were left blank, and a few had hand written personalized answers. The scaling methods between the four sub-surveys confused some patients. For example, the HHI scale includes four choices: strongly disagree, disagree, agree and strongly agree. Whereas, the SELSA-S is on a scale from 1 to 7 with 1 as disagree strongly and 7 as agree strongly. This highlights the degree of comprehension required for the questionnaire that may have been too advanced for this population.

\section{Strengths}

Strengths of the study design protected against bias; these included utilization of a theoretical model, measurement tools, timing and convenience, and scalability. The theoretical model provided clear definitions for the study variables. Quantitative methods were used and measurement tools were reliable and valid, which is especially important when compared to similar studies that use qualitative methods or unreliable instruments. Previous studies employing the FACIT-Sp have not consistently examined the subscales separately (i.e. 
Daugherty et al., 2005); examining the individual scores reveals meaningful differences that otherwise would be unnoticed (Murphy et al., 2010; Yanez et al., 2009). The survey was flexible in its timing and conveniently self-administered, which decreased possible barriers to completion (i.e. scheduling, proctor etc.). Even though only two patients completed the online survey, it was scalable with potential to gather large amount of data irrespective of time and additional effort.

\section{Conclusions}

Research lacks a widely disseminated, cohesive theoretical framework from which to assess spirituality (in the context of spiritual needs) and to implement SC (Peteet \& Balboni, 2013). As a result, it is difficult to practically incorporate spirituality and spiritual needs into a holistic care model. Several spiritual assessment tools exist, however, none were grounded in a theoretical model and there were no reliability or validity measures reported (Peteet \& Balboni, 2013). Furthermore, the authors concluded that most spiritual assessment tools, published after Monod and colleagues' (2011) systematic review of instruments measuring spirituality, seemed to measure religious activity rather than spiritual needs. Thus, a theoretical model that delineates the assessment of spiritual needs is paramount.

In palliative care patients, primarily affiliated with a Judeo-Christian religion, high levels of faith and hope may be able to predict spiritual wellness, which is having a sense of meaning and purpose. Anxiety (fear) was significantly inversely related to spiritual wellness. Loneliness also negatively correlated with spirituality, but was not significant. These results provide preliminary support of the relationships hypothesized by the FHLMSW. This was the first study to specifically test these relationships.

\section{Implications for Nursing}


Spiritual care has been considered an important component in palliative care, but often nurses feel unprepared to provide this type of care. The FHLMSW was originally "developed for the purpose of helping nurses better understand the spiritual nature of their patients" (Christman \& Mueller, 2015, p. 12). These preliminary findings may indicate that nurses can identify spiritual needs of faith, hope and love, based on the FHLMSW. Once spiritual needs are identified, the nurse will then be able to provide SC in those specific areas. 


\section{References}

Astrow, A. B., Wexler, A., Texeira, K., Kai He, M., \& Sulmasy, D. P. (2007). Is failure to meet spiritual needs associated with cancer patients' perceptions of quality of care and their satisfaction with care? Journal of Clinical Oncology, 25(36), 5753-5757. doi:10.1200/JCO.2007.12.4362

Balboni, M. J., Sullivan, A., Amobi, A., Phelps, A. C., Gorman, D. P., Zollfrank, A., .. . Balboni, T. A. (2013). Why is spiritual care infrequent at the end of life? Spiritual care perceptions among patients, nurses, and physicians and the role of training. Journal of Clinical Oncology, 31(4), 461-467. doi:10.1200/JCO.2012.44.6443

Balboni, T. A., Paulk, M. E., Balboni, M. J., Phelps, A. C., Loggers, E. T., Wright, A. A., ... Prigerson, H. G. (2010). Provision of spiritual care to patients with advanced cancer: Associations with medical care and quality of life near death. Journal of Clinical Oncology, 28(3), 445-452. doi:10.1200/JCO.2009.24.8005

Balboni, T. A., Vanderwerker, L. C., Block, S. D., Paulk, M. E., Lathan, C. S., Peteet, J. R., \& Prigerson, H. G. (2007). Religiousness and spiritual support among advanced cancer patients and associations with end-of-life treatment preferences and quality of life. Journal of Clinical Oncology, 25(5), 555-560. doi:10.1200/JCO.2006.07.9046

Balboni, T., Balboni, M., Paulk, M. E., Phelps, A., Wright, A., Peteet, J., . . Prigerson, H. (2011). Support of cancer patients' spiritual needs and associations with medical care costs at the end of life. Cancer, 117(23), 5383-5391. doi:10.1002/cncr.26221

Barss, K. S. (2012). T.R.U.S.T.: An affirming model for inclusive spiritual care. Journal of Holistic Nursing, 30(1), 24-34. doi:10.1177/0898010111418118 
Brady, M. J., Peterman, A. H., Fitchett, G., Mo, M., \& Cella, D. (1999). A case for including spirituality in quality of life measurement in oncology. Psycho-Oncology, 8(5), 417-428. doi:10.1002/(SICI)1099-1611(199909/10)8:53.3.CO;2-W

Bredle, J. M., Salsman, J. M., Debb, S. M., Arnold, B. J., \& Cella, D. (2011). Spiritual wellbeing as a component of health-related quality of life: The functional assessment of chronic illness therapy—spiritual well-being scale (FACIT-Sp). Religions, 2(1), 77-94. doi:10.3390/rel2010077

Bruera, E., Kuehn, N., Miller, M. J., Selmser, P., \& MacMillan, K. (1991). The Edmonton Symptom Assessment System (ESAS): A simple method for the assessment of palliative care patients. Journal of Palliative Care, 7(2), 6-9.

Butt, C. M. (2011). Hope in adults with cancer: State of the science. Oncology Nursing Forum, 38(5), E341-E350. doi:10.1188/11.ONF.E341-E350

Canada, A. L., Fitchett, G., Murphy, P. E., Stein, K., Portier, K., Crammer, C., \& Peterman, A. H. (2013). Racial/ethnic differences in spiritual well-being among cancer survivors. Journal of Behavioral Medicine, 36(5), 441-453. doi:10.1007/s10865-012-9439-8

Canada, A. L., Murphy, P. E., Fitchett, G., Peterman, A. H., \& Schover, L. R. (2008). A 3-factor model for the FACIT-Sp. Psycho-Oncology, 17(9), 908-916. doi:10.1002/pon.1307

Carron, R., \& Cumbie, S. A. (2011). Development of a conceptual nursing model for the implementation of spiritual care in adult primary healthcare settings by nurse practitioners. Journal of the American Academy of Nurse Practitioners, 23(10), 552-560.

Chien, C., Liu, K., Chien, H., \& Liu, H. (2014). The effects of psychosocial strategies on anxiety and depression of patients diagnosed with prostate cancer: A systematic review. 
International Journal of Nursing Studies, 51(1), 28-38.

doi:10.1016/j.ijnurstu.2012.12.019

Christman, S., \& Mueller, J. (2015). Faith-Hope-Love Model of Spiritual Wellness: A theoretical model of spirituality from a Christian worldview. Unpublished typescript.

Daugherty, C. K., Fitchett, G., Murphy, P. E., Peterman, A. H., Banik, D. M., Hlubocky, F., \& Tartaro, J. (2005). Trusting God and medicine: Spirituality in advanced cancer patients volunteering for clinical trials of experimental agents. Psycho-Oncology, 14(2), 135-146. doi:10.1002/pon. 829

DiTommaso, E., Brannen, C., \& Best, L. A. (2004). Measurement and validity characteristics of the short version of the social and emotional loneliness scale for adults. Educational and Psychological Measurement, 64(1), 99-119. doi:10.1177/0013164403258450

Herth, K. (1992). Abbreviated instrument to measure hope: Development and psychometric evaluation. Journal of Advanced Nursing, 17(10), 1251-1259. doi:10.1111/j.13652648.1992.tb01843.x

Hodge, D. R., \& Horvath, V. E. (2011). Spiritual Needs in Health Care Settings: A Qualitative Meta-Synthesis of Clients' Perspectives. Social Work, 56(4), 306-316. doi:10.1093/sw/56.4.306

Hoffman, B. M., Zevon, M. A., D'arrigo, M. C., \& Cecchini, T. B. (2004). Screening for distress in cancer patients: The NCCN rapid-screening measure. Psycho-Oncology, 13(11), 792799. doi:10.1002/pon.796

Holland, J. C. (1999). Update: NCCN practice guidelines for the management of psychosocial distress. Oncology, 13(11A), 459-507. 
Kandasamy, A., Chaturvedi, S., \& Desai, G. (2011). Spirituality, distress, depression, anxiety, and quality of life in patients with advanced cancer. Indian Journal of Cancer, 48(1), 55. doi:10.4103/0019-509X.75828

Koenig, H. G. (2012). Religion, spirituality, and health: The research and clinical implications. ISRN Psychiatry, 2012, 1-33. doi:10.5402/2012/278730

Kristeller, J. L., Rhodes, M., Cripe, L. D., \& Sheets, V. (2005). Oncologist assisted spiritual intervention study (Oasis): Patient acceptability and initial evidence of effects. The International Journal of Psychiatry in Medicine, 35(4), 329-347. doi:10.2190/8AE4F01C-60M0-85C8

Meehan, T. C. (2012). Spirituality and spiritual care from a Careful Nursing perspective. Journal of Nursing Management, 20, 990-1001. doi:10.1111/j.1365-2834.2012.01462.x

Mickley, J. R., Soeken, K., \& Belcher, A. (1992). Spiritual well-being, religiousness and hope among women with breast cancer [abstract]. Journal of Nursing Scholarship, 24(4), 267272. doi:10.1111/j.1547-5069.1992.tb00732.x

Monod, S., Brennan, M., Rochat, E., Martin, E., Rochat, S., \& Büla, C. J. (2011). Instruments Measuring Spirituality in Clinical Research: A Systematic Review. Journal of General Internal Medicine, 26(11), 1345-1357. doi:10.1007/s11606-011-1769-7

Murphy, P. E., Canada, A. L., Fitchett, G., Stein, K., Portier, K., Crammer, C., \& Peterman, A. H. (2010). An examination of the 3-factor model and structural invariance across racial/ethnic groups for the FACIT-Sp: A report from the American Cancer Society's Study of Cancer Survivors-II (SCS-II). Psycho-Oncology, 19(3), 264-272. 
Musarezaie, A., Esfahani, H. N., Ghaleghasemi, T., Kariamian, J., \& Ebrahimi, A. (2012). The relationship between spiritual wellbeing and stress, anxiety, and depression in patients with breast cancer [abstract]. Journal of Isfahan Medical School, 30(195).

National Comprehensive Cancer Network (NCCN). (2013). NCCN clinical practice guidelines in oncology: Distress management.

National Concensus Project for Quality Palliative Care. (2013). Clinical practice guidelines for quality palliative care, third edition. Pittsburg: National Consensus Project for Quality Palliative Care.

Niespodziani, C. A., \& Hepola, B. A. (2011). The 2011 CMS-Joint Commission crosswalk: A side-by-side analysis of the CMS conditions of participation and the Joint Commission standards. Danvers, MA: HCPro.

Pearce, M. J., Coan, A. D., Herndon, J. E., Koenig, H. G., \& Abernethy, A. P. (2012). Unmet spiritual care needs impact emotional and spiritual well-being in advanced cancer patients. Supportive Care in Cancer, 20(10), 2269-2276. doi:10.1007/s00520-011-1335-1

Pehlivan, S., Ovayolu, O., Ovayolu, N., Sevinc, A., \& Camci, C. (2012). Relationship between hopelessness, loneliness, and perceived social support from family in Turkish patients with cancer. Supportive Care in Cancer, 20(4), 733-739. doi:10.1007/s00520-011-1137-5

Peteet, J. R., \& Balboni, M. J. (2013). Spirituality and religion in oncology. CA: A Cancer Journal for Clinicians, 63(4), 280-289. doi:10.3322/caac.21187

Peterman, A. H., Fitchett, G., Brady, M. J., Hernandez, L., \& Cella, D. (2002). Measuring spiritual well-being in people with cancer: The functional assessment of chronic illness therapy_-spiritual well-being scale (FACIT-Sp). Annals of Behavioral Medicine, 24(1), 49-58. doi:10.1207/S15324796ABM2401_06 
Phelps, A. C., Lauderdale, K. E., Alcorn, S., Dillinger, J., Balboni, M. T., Wert, M. V., .. . Balboni, T. A. (2012). Addressing spirituality within the care of patients at the end of life: Perspectives of patients with advanced cancer, oncologists, and oncology nurses. Journal of Clinical Oncology, 30(20), 2538-2544. doi:10.1200/JCO.2011.40.3766

Philip, J., Smith, W. B., Craft, P., \& Lickiss, N. (1998). Concurrenty validity of the modified Edmonton Symptom Assessment System with the Rotterdam Symptom Checklist and the Brief Pain Inventory. Support Cancer Care, 6, 539-541.

Phillips-Salimi, C. R., Haase, J. E., Kintner, E. K., Monahan, P. O., \& Azzouz, F. (2007). Psychometric properties of the herth hope index in adolescents and young adults with cancer. Journal of Nursing Measurement, 15(1), 3-23. doi:10.1891/106137407780851769

Richardson, L. A., \& Jones, G. W. (2009). A review of the reliability and validity of the Edmonton Symptom Assessment System. Current Oncology, 16(1), 53-64. doi:10.3747/co.v16i1.261

Rosenfeld, B., Pessin, H., Lewis, C., Abbey, J., Olden, M., Sachs, E., . . Breitbart, W. (2011). Assessing hopelessness in terminally ill cancer patients: Development of the Hopelessness Assessment in Illness Questionnaire. Psychological Assessment, 23(2), 325-336. doi:10.1037/a0021767

Sahin, Z. A., \& Tan, M. (2012). Loneliness, Depression, and Social Support of Patients With Cancer and Their Caregivers. Clinical Journal of Oncology Nursing, 16(2), 145-149. doi:10.1188/12.CJON.145-149

Spiegel, A. (2005, January 3). The dictionary of disorder: How one man revolutionized psychiatry. The New Yorker. Retrieved December 2, 2014, from 
http://www.newyorker.com/magazine/2005/01/03/the-dictionary-ofdisorder?currentPage $=$ all

Spitzer, R. L., Kroenke, K., Williams, J. B., \& Lowe, B. (2006). A brief measure for assessing generalized anxiety disorder: The GAD-7. Archives of Internal Medicine, 166(10), 10921097. doi:10.1001/archinte.166.10.1092

Sulmasy, D. P. (2002). A biopsychosocial-spiritual model for the care of patients at the end of life. The Gerontologist, 42(Supplement 3), 24-33. doi:10.1093/geront/42.suppl_3.24

Vallurupalli, M., Lauderdale, K., Balboni, M. J., Phelps, A. C., Block, S. D., Ng, A. K., . . Balboni, T. A. (2012). The role of spirituality and religious coping in the quality of life of patients with advanced cancer receiving palliative radiation therapy. The Journal of Supportive Oncology, 10(2), 81-87. doi:10.1016/j.suponc.2011.09.003

Van Dover, L., \& Pfeiffer, J. B. (2007). Spiritual care in Christian parish nursing. Journal of Advanced Nursing, 57(2), 213-221. doi:10.1111/j.1365-2648.2006.04081.x

Watanabe, S. M., Nekolaichuk, C., Beaumont, C., Johnson, L., Myers, J., \& Strasser, F. (2011). A multicenter study comparing two numerical versions of the Edmonton Symptom Assessment System in palliative care patients. Journal of Pain and Symptom Management, 41(2), 456-468. doi:10.1016/j.jpainsymman.2010.04.020

Watts, S., Leydon, G., Birch, B., Prescott, P., Lai, L., Eardley, S., \& Lewith, G. (2014). Depression and anxiety in prostate cancer: A systematic review and meta-analysis of prevalence rates. BMJ Open, 4:e003901, 1-9. doi:10.1136/bmjopen-2013-003901

Whitford, H. S., \& Olver, I. N. (2012). The multidimensionality of spiritual wellbeing: Peace, meaning, and faith and their association with quality of life and coping in oncology. Psycho-Oncology, 21(6), 602-610. doi:10.1002/pon.1937 
Winkelman, W. D., Lauderdale, K., Balboni, M. J., Phelps, A. C., Peteet, J. R., Block, S. D., . . . Balboni, T. A. (2011). The relationship of spiritual concerns to the quality of life of advanced cancer patients: Preliminary findings. Journal of Palliative Medicine, 14(9), 1022-1028. doi:10.1089/jpm.2010.0536

World Health Organization (WHO). (2014). WHO definition of palliative care. Retrieved March 21, 2014, from http://www.who.int/cancer/palliative/definition/en/

Yanez, B., Edmondson, D., Stanton, A. L., Park, C. L., Kwan, L., Ganz, P. A., \& Blank, T. O. (2009). Facets of spirituality as predictors of adjustment to cancer: Relative contributions of having faith and finding meaning. Journal of Consulting and Clinical Psychology, 77(4), 730-741. doi:10.1037/a0015820

Yang, Y., Liu, L., Wang, Y., Wu, H., Yang, X., Wang, J., \& Wang, L. (2013). The prevalence of depression and anxiety among Chinese adults with cancer: A systematic review and meta-analysis. BMC Cancer, 13(1), 393. doi:10.1186/1471-2407-13-393 